\title{
Trends of Pakistani films: An analytical study of restoration of cinema
}

\author{
Fouzia Naz* \\ Sadia Mehmood**
}

\begin{abstract}
People prefer to go to the cinema as compared to theaters because of its way of execution and performance. Background music, sound effects, lights, direction attract people, and its demonstrations relate people to their lives. It is true that films have a unique and powerful connection between human behavior and societal culture. Pakistani film industry faced the downfall and now it is doing its best to make the films on international standards. In this research article, the background of Pakistani cinema and causes of downfall will be discussed. The main idea of this research article is to identify and study the development of Pakistani film industry. Qualitative and quantitative data collection will be used as the research method of this research. This research article helps in observing different mass media theory based on Pakistani cinema. Moreover, it will be explained what filmmakers critiques and people say regarding revival or restoration.
\end{abstract}

Keywords: downfall, revival, the impact of the Pakistani film industry, Lollywood

*Assistant professor, Mass Communication, University of Karachi)

**Assistant professor, Mass Communication, University of Karachi) 
The definition of cinema can be explained as "another word of moving a picture"1This is the place where films are shown to the public. Most of the people who are not into the arts get confused in cinema and theater. The theater is the building where live performance is performed ${ }^{2}$. The similarity between cinema and theaters are both of them execute act and created for public entertainment. In Pakistan, cinema has suffered a lot while is played a vital role in the promotion of own culture and act as the transmission of others culture to the people of Pakistan. Its significance can be measured as it was considered as the fourth largest featured film producing country ${ }^{3}$. These days, the flourishing of Pakistani cinema has been seen and its aims are to deliver entertainment and education to the audience ${ }^{4}$.

The concept of cinema is evolved from 1600 (storytelling from shadows). Moreover, in the 1830 s, people started to find ways to make picture moving and that happened with the help of scientific equipment and concepts "persistence of vision". The art promoters figured out many ways to develop this area even further and many developments were observed on literature and philosophy. The first moving picture was "moving horse" which was made by the movement of 24 pictures by Edward Muybridge in 1878. In 1891, Thomas Edison and assistant William Dickson invented the first camera to record movement. The silent era started in 1895 by Lumiere Brothers (LB)and pushed the boundaries of experimentation where silent and black \&white films were used to make(first public screening was offered)and this era ended in 1929. LB introduced a package of six films in the subcontinent in 1896 at Bombay and from then films started to release on a daily basis. Raja Harishchandra was the first silent films made in the subcontinent and until 1930, around 200 films used to release per annum. The super hit sounded film was Alam Ara in 1931 and film industry had gone successful 5 .

The history of Pakistani film industry started from 1929 by setting up a studio (by Abdur Rashid under the partnership) that turned into

1 www. indiacelebrating.com. IMPACT OF CINEMA IN LIFE ESSAY. April 12, 2017. https://www.indiacelebrating.com/essay/impact-of-cinema-in-life-essay/

2 Witka, Amber. The Differences Between Live Theatre And Film. December 12, 2016. https://www.theodysseyonline.com/differences-live-theatre-film.

3 Erum, Hafeez. Pakistani Cinema through a transitional lens. June 2015. https://www.researchgate.net/publication/303898261_Pakistani_Cinema_through_a_tr ansitional_lens

4 Hassan, Zaidi. What makes the revival of Pakistani cinema an uphill task. February 10, 2017. https://herald.dawn.com/news/1153991.

5 Renu, Saran. History of Indian Cinema. Diamond Pocket Books Pvt Ltd, 2017. 
establishment "Playart Phototone" (the foundation of Lahore film industry). He had to face many challenges in shooting and bore the loss of equipment because of the rough traveling area. Finally, he made a film on their standard "Husn ka Daku" and succeeded. After success, Roop Lal Shori (in 1932) set up business in Lahore, Sajjad Gul (1946) set up the studio in Multan, and 'Eveready Pictures' was set up (bigger production house than any) ${ }^{6}$. After independence, the Pakistani film industry faced problems such as lack of equipment, etc. but Lahore turned into the center of silver screening because of picking up British autonomy. In the beginning, the first film "Teri Yaad" was released and did not do well, the other films also got no attention until 19507. "Do Ansoo" revived the Pakistani cinema. Many singers, actors, artists, art directors got fame between the periods of 1950 to 1980. After the 80s, the downfall was observed due to the same scripts and poor execution of the art. The revival of the Pakistani film industry was observed in 2007 when Khuda Kay Liye was released and then improvements were seen in every movie till $2019^{8}$.

According to Tom Shirak, the role of films and cinema in society is imperative (for cultural and economic aspects) and the great films are remembered for centuries. Although, piracy of films and international films on internet cease the impact on people what filmmakers want to deploy ${ }^{9}$. The significance of this research article can be identified from its impact on people in the developing world. The execution of art and performance create a drastic change in the mindset of people as well as creating international standards. Here international standard means Hollywood and Bollywood films. Although, there is no comparison between Pakistani and Hollywood films Bollywood can be compared due to the historical background. Therefore, the major question is whether Pakistani Cinema is still surviving (for not to lose its identity) or it is reviving (re-energizing).

The main idea of this research article is to identify and study the development of Pakistani film industry. As people say, watching the movie

6 Sundararaj, Theodore,Baskaran. History through the lens: perspectives on South Indian cinema. 2009

7 Ali, Khan:Ali,Nobil,Ahmed. Cinema and Society: Film and Social Change in Pakistan. Oxford University Press, 2016.

8 Sagar, Sami. A Brief History Of Pakistani Film Industry - And Its Revival(S). January 4, 2017. http://blogs.dunyanews.tv/19359/.

9 Ali, Khan:Ali,Nobil,Ahmed. Cinema and Society: Film and Social Change in Pakistan. Oxford University Press, 2016. 
can be revitalizing so, this article will also focus on whether Pakistani films make people refreshed or not. Moreover, this research will clarify that improvement of equipment (technical expertise) has created the standard of the Pakistani film industry. In addition, it will be observed why people want to go to watch Pakistani films.

The revival of the Pakistani film industry is caused by continues downfall of the industry. As it is mentioned above after 2007, Pakistan started to make sensible films but the not only cinema was responsible to attract people, many private TV channels were made to promote them. The main purpose of these channels is to attract people by their own art and create awareness regarding it $^{10}$. In promoting art, Indian director and producer Mahesh Bhatt came to Pakistan to hunt talented Pakistani singers and actors to work in India for his films. He actively participates in third Kara film festival and had the screening of his movie "Paap" and later on, he approached Atif Aslam and Meera of his other projects ${ }^{11}$. After some time, Film Producers Association (FPA) and Cinema Owner Association (COA) were demanded to remove the ban from Indianfilms on Pakistan and the government considered that demand. After the ban, Mahesh Bhatt said, "Now Pakistan is on new lease of life". He further said, "The banning of Indianfilms were started from 1968 and the field or art got limited because of no transmission of culture. Good scripts were used to be rejected, and vulgarism in the name of art used to be promoted. This period for the Pakistani film industry was responsible for the gap of qualified content and storywriters and they were compelled to leave the industry. On the other hand, decent families made a negative perception regarding the Pakistani film industry that is why people started to peruse Indian films. In addition, vulgar and senseless films were not only responsible for the damaging Pakistani film industry but also poor investment, weak decision making in projects, and unprofessional attitude destroyed the whole industry." 12

10 Erum, Hafeez. Pakistani Cinema through a transitional lens. June 2015. https://www.researchgate.net/publication/303898261_Pakistani_Cinema_through_a_tr ansitional_lens.

11 Ghafoor, Usman. Pakistan's dilemma - Bollywood or bust? June 9, 2005. http://news.bbc.co.uk/2/hi/south_asia/4617447.stm.

12 Aslam. Lollywood - Pakistani Cinema Through A Transitional Lens. 2016. https://web.b.ebscohost.com/abstract?direct=true\&profile=ehost\&scope=site\&authtyp $\mathrm{e}=$ crawler\&jrnl=19984162\&AN=117676327\&h=j3GhOr7fsTqTh523spH3FKnFfWUQWZ rWgoPu8c9cwj6l3xmw\%2bKtCGqAFcJkdWk9\%2fsHhjLjn\%2bOfvZKIvEc0vEdA\%3d\%3 $\mathrm{d} \& \mathrm{crl}=\mathrm{c} \&$ resultNs=AdminWebAuth\&resultLo. 
The topic of the restoration of the Pakistani film industry is the most discussed topic after 2010 but unlike before, the improved and new cinema does not hit the interest of masses ${ }^{13}$. If the city Hyderabad is considered, in the mid-90s, 21 cinemas were running progressively where Bollywood and Hollywood films were used to present against reasonable consideration. Those days were the golden days for the Pakistani industry not because of Hyderabad but all the urban community ${ }^{14}$. The biggest intention of productivity (for the industry) and acceptance (by people) of films is not by any cultural or religion or moral side but the low-ticket price. After restoration specifically after 2007 , one elite community were used to go to the cinema and still only elite or upper-middle-class people (who can afford tickets of whole family members) go to watch the film ${ }^{15}$.

The films are the visual way of storytelling and transferring the idea to the people in an influential manner ${ }^{16}$. In the creative stories, many stereotypes have changed in the Pakistani film industry such as a male lead is considered as the hero whereas female lead remains second lead. Now the trends have changed, female-oriented films are being made such as Cheekh, Bol, Dukhtar, Motorcycle girl and more. Consequently, as the creative scripts are coming up, expansion of the industry in the international forum has seen. These films deliver international recognition as well ${ }^{17}$.

This research article is the result of many mass media theories. Top three theories, which are used in order to proceed with this research, are critical theory, uses and gratification theory, and cultivation theory. The uses and gratification theory refers to the people's (mass audience) gratification against media. This approach is about how media satisfies the needs of people by presenting what they want to watch. This theory considers people like the active users of media and primary purpose is acceptance and interpretation of idea/information/knowledge in their lives. This theory says that people are responsible for adopting anything that comes up on media,

13 Ali, Khan:Ali,Nobil,Ahmed. Cinema and Society: Film and Social Change in Pakistan. Oxford University Press, 2016.

14 Hassan, Zaidi. What makes the revival of Pakistani cinema an uphill task. February 10, 2017. https://herald.dawn.com/news/1153991.

15 Ali, Khan:Ali,Nobil,Ahmed. Cinema and Society: Film and Social Change in Pakistan. Oxford University Press, 2016.

16 Geoffrey, Nowell-Smith. The History of Cinema: A Very Short Introduction. Oxford University Press, 2017

17 Hassan, Zaidi. What makes the revival of Pakistani cinema an uphill task. February 10, 2017. https://herald.dawn.com/news/1153991. 
which satisfy their needs and demands. On the other hand, sometimes this theory fails from the side of the audience (what they actually want to see on media). There are four areas where this theory is applicable are entertainment (involve television channels, internet, cinema, radio, and print tabloid), social interaction (discussion media with your close ones can also satisfy people), personal identity (stars and role model satisfy people) and information (education, knowledge, character building etc.). Therefore, the filmmakers use these four areas to influence and satisfy people ${ }^{18}$.

The other theory, which will apply in this research article, will be the critical theory. To apply this theory, content and media will be considered. This theory refers to the reflective critique and assessment of culture and society with the help of knowledge of humans and social sciences. This theory divides into two forms. First is the cultural study, which focuses on the significance of text (semiotic and linguistic perspective). It is about the debate that content creators are elite and consumers are the mass audience that creates the class system. Furthermore, content is created after the consent of elites. The second one is societal/political/economic studies. It means content and media is ruled by big organizations and direct people accordingly. Both the areas (cultural and societal) are about creating a nonculture society in which they can change attitudes and behavior of people ${ }^{19}$. Therefore, Pakistani films are more into reviving and creating a new mindset regarding the Pakistani film industry.

The third theory, which will apply in this research article, is cultivation theory, and it will be performed on the terms of creating social reality. This theory refers to the perception of reality by the audience against mass media. This theory talks about the more people are involved in media the more it leaves an impact on them ${ }^{20}$. This theory was basically about television but in this case, cultivation of the habit of watching films will be the subject of discussion.

18 Syed, Arabi,Idid. Uses and Gratifications. July 2012. https://www.researchgate.net/publication/299566021_Uses_and_Gratifications.

19 www.iep.utm.edu. The Frankfurt School and Critical Theory. 2015. https://www.iep.utm.edu/frankfur/.

20 masscommtheory.com. Cultivation Theory. 2015. https://masscommtheory.com/theoryoverviews/cultivation-theory/. 
The research methodology helps in planning and organizing how certain research will going to be performed ${ }^{21}$. This research is about the impact of the restoration of the Pakistani film industry, an ordinary people and their response. Through qualitative and quantitative methods, research will be conducted. In qualitative research (non-numeric), the in-depth interview will be conducted with the concerned ones of the Pakistani film industry (directors, producers, actors, scriptwriters, and technical staffs). Moreover, for gathering secondary information, books and articles that are available on the internet will be reviewed.

The other method to do this research is quantitative research. The method does not deal will articles or any non-numeric form. It deals will the numbers and that information that can be easily measurable. It will answer many problems frequently in the form of numbers. In order to do research for this topic, survey research method will be conducted. In this research method, large population answers the survey and these days online survey solve the problem to gather data from the mass audience regarding a certain topic. For this research, after collecting the data, it will be analyzed and summarized in tabulate and meaningful way.

The sampling size of this research will be random people (online users) while the time horizon to perform this research is limited. Therefore 150 respondents will be enough to analysis their answers and the target audience will be the online users of Karachi, Pakistan. The research instrument for this research will be a questionnaire, which includes 14close-ended questions as per the hypothesis of this research (causes and reasons for the restoration of the Pakistani film industry).

With the help of these data collection, it will be identified whether revival has really happened or not. it will be identified that current films are watchable or not, and the content, script, acting, and direction has improved or not. Are people willing to invest their time and money in these films or not. These are the main questions that will be answered after analyzing their data collection.

21 Clarke, R. Research Models and Methodologies . University of Wollongong (UOW), 2005. 


\section{Secondary data and qualitative collection}

In this area, 13 top films of 2017 will be focused that ignites the fire of revival in Pakistani in the film industry. These films are selected because these are most reviews and every Pakistani at least know its pilot if they did not watch the whole movie. Reviews and pilots are explained below

Khuda kay liye by Shoaib Mansoor: This film was about the Islamic values and western world. Shan, Fawad, and Iman Ali played lead characters of that film. The main idea of this film is to show the double standard of people in the name of Islam. Such as one rock musician (Shan) was brainwashed by an Islamic extremist. The crisis occurs in the life of other (Fawad) and Iman Ali who was living in London and loves English man, sent back to Pakistan to settle there. People of Pakistan appreciate the new script and concept. Although this film does not hit the interest of masses because still some people consider this as propaganda against Islam but still it succeeded to create awareness in people 22 .

Thora Jee le by Rafay Rashdi: The story of the film revolves around six characters. The film is almost about the reunion of six friends and after reunion, tragedies start to happen. The hazy plot, misplacement of songs and the immature movie lost the interest of people sitting in the cinema hall. Due to this foggy plot, people started to concern about whether it is really a revival of the cinema of industry is making them fool again ${ }^{23}$.

Raasta by Sahir Lodhi: this film is about the revenge of drug dealers against honest police officer and his family. This film looks like the remake of some Bollywood movie because of item song, while people rejected acting of Sahir Lodhi. On many websites, review of Raasta is worst ${ }^{24}$.

Chaly they Sath by Umer Ali: This film is about Pakistan tour where the entire friend decides to do have toured and then they got new friends in the

22 Malani, Gaurav. Khuda Kay Liye: Movie Review. March 31, 2008. https://economictimes.indiatimes.com/industry/media/entertainment/khuda-kay-liyemovie-review/articleshow/2913371.cms.

23 Momina, Mindeel. Film Review: Thora Jee Le. January 23, 2017. https://www.youlinm agazine.com /story/film-thora-jee-le-review/NzU0

24 Shahid, Sana. Film Review: 'Raasta'. April 3, 2017. https://www.youlinmagaz ine.com/story/film-raasta-review/ODA5. 
journey. This movie created a positive impact on people in many ways such is it showed the importance of friends and the beauty of Pakistan ${ }^{25}$.

Mehrunisa V Lub U by Yasir Nawaz: This movie is a socio-romantic movie. It is about childhood love and struggles to cease her wedding with another man. There is nothing new in the movie and feedback from people was average. People claim that most of the scenes are copied from Bollywood films ${ }^{26}$.

Yalghaar by Hassan Rana: This film was about passionate officers that performed the military operation. Actors and director worked hard in the promotion, and create hype to capture an audience but still failed to create a lasting impact on them ${ }^{27}$.

Chain Aye Na by Syed Noor: The plot is, a musician falls in love with a woman but she has already in love with someone. No one came to watch this movie and those who watched it regrets their money ${ }^{28}$.

Saawan by Farhan Alam: this film is about a disabled child who founds difficulties in the dessert. Although this film was nominated for many international awards (because of the real issue) but it failed to make an emotional appeal in public ${ }^{29}$.

Balu Mahi by Haissam Hussain: a plot is, a man crashes a wrong wedding but girls willingly to seize the opportunity to run with him. The direction was decent but looks like the script is inspired by the "Jab We Met" and "Dil Boly Harippa". People did not hate the movie but still not love it ${ }^{30}$.

25 Mahmood, Rafay. Chalay Thay Saath review: A beautifully bad film. Aril 21, 2017. https://tribune.com.pk/story/1390043/chalay-thay-sath-review-beautifully-bad-film/.

26 Ashraf, Sonia. Review: Mehrunisa $V$ Lub U. June 24, 2017. https://images.dawn.com/news/1177883/review-mehrunisa-v-lub-u-is-an-eid-filmthe-whole-family-cant-watch-together.

27 - Yalghaar review. june 22, 2017. https://tribune.com.pk/story/1441941/yalghaarreview-bullets-bombs-bad-storytelling/.

28 Javed, Aiman. Film Review: 'Chain Aye Na'. August 17, 2017. https://www.youlinm agazine.com/story/film-chain-aye-na-review/OTE0.

29 Noor-Ul-Ain. Film Review: Saawan. September 19, 2017. https://www.youlinma gazine.com/story/pakistani-film-saawan/OTM4.

30 Hassan, Zaidi. What makes the revival of Pakistani cinema an uphill task. February 10, 2017. https://herald.dawn.com/news/1153991. 
Verna by Shoaib Mansoor: Plot is, a happily married couple got crisis when the wife got kidnapped and raped. She faces the challenges from his own family and society as well. Main lead educates to women to be strong and face the society. This movie did well and succeeded to aware people regarding this issue ${ }^{31}$.

Rangreza by Amir Muhiuddin: Plot is, a girl who is engaged since childhood caught with the pop star. This film is about prejudgment and the ugly face of society. People did not enjoy this film through this creates hype all over the media. People find it boring and full of negativity ${ }^{32}$.

Panjab Nahi Jaungi by Nadeem Baig: this movie is about a man want to impress and wins the heart of a woman he loves. Critics and masses appreciated this movie because of its storytelling, dialogs, and theme ${ }^{33}$.

Na Maloom Afraad 2 by Nabeel Qureshi: Plot is three Hapless men looking for big robbery and things gone wrong. This movie is better than Na Maloom Afraad 1. People liked it and it is a good comedy movie ${ }^{34}$.

Above are the reviews and plot of some Pakistan films that are considered as secondary data in order to analyze the development and revival of the Pakistani film industry. Moreover, for the primary qualitative data collection, in-depth interview with different prominent personalities is held regarding their production, writing, cinematography, and direction.

\section{As per the in-depth interview}

Production department in the backbone on the success of the business. $\mathrm{He} / \mathrm{she}$ is responsible for planning the budget, casting, expenses, script, shooting, editing, and recording. It is the duty of a producer to promote,

31 www.reviewit.pk. Punjab Nahi Jaungi - Film Review. September 1, 2017. https://reviewit.pk/punjab-nahi-jaungi-film-review/.

32 Aijaz, Rahul. $\mathrm{Na}$ Maloom Afraad 2 review. September 1, 2017. https://tribune.com.pk/story/1496720/na-maloom-afraad-2-review-entertainingsoulless/.

33 www.reviewit.pk. Punjab Nahi Jaungi - Film Review. September 1, 2017. https://reviewit.pk/punjab-nahi-jaungi-film-review/.

34 Aijaz, Rahul. Na Maloom Afraad 2 review. September 1, 2017. https://tribune.com.pk/ story/1496720/na-maloom-afraad-2-review-entertaining-soulless/. 
advertise and hire distributors nationally and internationally. Syed Noor says that the Pakistani film industry is going to get more success. He adds that these days scriptwriters are coming up with creative stories, which are undoubted of international standards. People of Pakistan now prefer Pakistani films as compared to Bollywood. The film critic Human Zubair says, everything works in its own sphere. However, Bilal Lashari says good production value, standard, and qualified scripts are what really matter.

Script writing is a difficult procedure because it drives from their own existing thoughts. The scriptwriter is the one who will remain responsible for the mood of the situation, acting, environment, and characters. In Pakistan, most of the film writers are the television drama writers and this is the biggest flaw in this industry. In a 2-hour movie, people expect to watch a movie of international standards. The other drawback is the lack of creativity, which means, the biggest chunk of creativity such as biopic, realistic scripts, events, history, future, horror, and Mistry is missing. Hollywood and Bollywood never ignore these genres in their industries. Although, the Pakistani film industry is revealing so there is a long way to go. For cinematography, Rana Kamran who is one of the best cinematographers says that Mahe-e-Mir is the hardest job in terms of cinematography because it involves past, present and dark lights. After that movie, Pakistani cinematographers started to do their best in presenting appreciable performance. Modern day's cinematographers are much aware of camera angles and positions and this dedication make any average scripted movie to look beautiful.

The film director is the one who visualizes the script and organizes the team to perform certain duties to accomplish the required result. It is the responsibility of the director to measure the execution of performance against planning. Film director hires actors, looks into production design, and creative aspects. In this scenario, Agha Hasan Askari (a well-known director) says that the major causes of the downfall of the Pakistani film industry are the lack of investment and unprofessional cast and crew. Now people are professional and they know their job. Trained director, staff and actors are the major reason for the success of Pakistani film industry now. However, Nabeel Qureshi and Fizza Ali say that director analyzes whether the actor is fit for role or script or not. 


\section{Qualitative data collection}

In the survey 150 people participated in which 63 (42\%) were female and 87 (58\%) were male. in addition, through survey age between 18 to 24 were 96 people (64\%), between 25 to 30 were $33(22 \%)$ and 30+ was $21(14 \%)$. In the first questions "do you like films?" in response, 44\% people said 'yes', $31 \%$ people responded 'no', 17\% people responded 'sometimes' and 8\% people responded 'it's my relaxing activity'.

The second question was, which film industry you love the most? In response, $48 \%$ of people like Pakistani films, $11 \%$ of people like regional films, $21 \%$ of people responded to Bollywood films, and $70 \%$ responded to Hollywood films. The reason people chose Hollywood is its qualified standard.

The third question was "do you watch films in cinema?" in responses 38\% people responded 'yes', 15\%people responded 'no', 7\%people responded 'if cinema is near' and $40 \%$ people responded 'I watch films at home'. It means the audience feel comfortable (going to the cinema and bear ticket expense) watching films at home.

The fourth question was "what type of movie you prefer to watch?" $15 \%$ people responded 'romantic films', $32 \%$ people responded 'comedy films', $27 \%$ people responded 'action films', $22 \%$ people responded 'horror films', and $4 \%$ people responded 'biopic'.

The fifth question was "do Pakistani films are the copy of Bollywood films?" $64 \%$ of people responded 'yes' and $26 \%$ of people responded 'no'. It means, there is a perception in Pakistanis scripts are the same as Bollywood so it is better to watch their films.

The other question was "Pakistani cinema is making better films as compared to old ones?" in response, $82 \%$ people said 'yes', $15 \%$ people said 'no' and 53\% people responded 'maybe'. The other question was also about the performance of the Pakistani film industry. The question was 'are people willing to see the transition of the Pakistani drama industry to the Pakistani film industry?' In response, $22 \%$ of people said 'yes it is okay to have transition 0 to 25 percent'. $40 \%$ of people responded 'it is okay to have 20 to $50 \%$ transition'. $21 \%$ of people responded, 'it is okay to have 50 to $75 \%$ 
transition'. 2\% responded, it is okay to have 75 to $100 \%$ transition and $13 \%$ responded that transition is not acceptable.

The eighth question was 'do we need any new faces for international presence?' $25 \%$ of people responded 'no' and 75\% of people responded 'yes'. In other question was 'what are the impact on Pakistani film industry on people? People responded, 54\% people said it has a cultural effect, $28 \%$ said it has no impact, $8 \%$ said it has an effect on the mind, $4.6 \%$ said it has a physical impact and other $5 \%$ said it has an emotional impact.

In the $10^{\text {th }}$ question was 'how efficient is the Pakistani film industry?' $34 \%$ People responded that $7 / 10,7 \%$ responded $7.5 / 10,30 \%$ responded $8 / 10$, $8 \%$ responded 9/10, 11\% responded 9.5/10, 14\% responded 3/10, 15 responded 4.5/10, 19\% responded 5/10, 12\% responded 6/10.

The $11^{\text {th }}$ question was about 'do films reflect realistic society?' in response, $14 \%$ of people say 'not sure', $31 \%$ of people say 'yes' and 55\%people responded 'no'.

The $12^{\text {th }}$ question was about 'Do other filmmaking departments such as cinematography, writing, production, and direction are advancing or not?' in response, $71 \%$ people say 'yes', $25 \%$ people say 'no' and $4 \%$ people say maybe.

The $13^{\text {th }}$ question was about "what do you think the estimated percentage of impact on the culture of the Pakistani film industry on people? In response, $41 \%$ people responded 0 to $20 \%$, 83 people responded 20 to $40 \%, 19 \%$ people responded 40 to $60 \%$ and $7 \%$ people responded 60 to $80 \%$.

The $14^{\text {th }}$ question was about, how often you watch films? In response, $53 \%$ of people responded weekly, 39\%people responded monthly, $47 \%$ of people responded daily and 11\%people responded rarely.

The $15^{\text {th }}$ question was about 'which is your favorite Pakistani movie?' In response $40 \%$ people responded "actor in law", 20\% people responded ' $\mathrm{Na}$ Maloom Afraad'16\% people responded 'Teefa in Trouble', 9\%people responded 'Manto' and 14\% people responded 'none'. 


\section{Findings, analysis, and discussion of qualitative data collection}

According to the 15 films, which are explained above, reflects that they are some kind of copying of Bollywood films no matter how they represent (cinematography, direction, and storyline). However, in most of the films, Pakistani culture has represented in terms of language, dressing, and lifestyle. The disapproval arises when the portrayal of women represents the wrong image of Pakistan such as people in Pakistan does not usually wear short skirts (what Hania Amir wore in Na Maloom Afraad 2). Panjab Nahi Jaungi is appreciated regarding cinematography and delivering of dialogues and did the business of 480 million worldwide (record breaking).

If the plotting side is considered, most of the release of 2017 are divulged us that good cinematography can create a good storyline. Storywriters or scriptwriters had been careless in writing the same stories that Pakistanis have been watching for years (from Bollywood). By conducting an in-depth interview, it clears the doubt of survival of industry or revival of the industry. Producers, writers, cinematographer, and directors are agreed that before a few decades, people in this field were untrained and unprofessional. They stated the biggest reason for downfall was lack of investment and now an industry in reviving because of investment in the films. They proposed that the government should invests more in this industry of IFCB (Islamabad film censored board) remove censorship in some areas; the industry will be able to compete with international standards. However, the finding of this research verified that new films are far better than the previous one (before 2007).

\section{Findings, analysis, and discussion on quantitative data}

The finding of the study says both men and women are actively participating in watching films. Moreover, it disclosed that people prefer watching films at homes, people prefer watching Hollywood films and then Pakistani films, most of the Pakistanis like to watch a comedy films, and people think Pakistani films are copying Bollywood films in term of dance items and overacting. In addition, people find new films are far better than old ones, 25$50 \%$ people accept the transition of Pakistani drama industry to the Pakistani film industry, and people prefer new actors to represent youth. Moreover, people think that major impact of films is over culture, people claim most of the films are not realistic, prefer to watch films weekly, and according to a survey, the most favorite movie is Actor In Law. 


\section{Conclusion}

This research article was about the impact of the revival of the Pakistani film industry after the downfall. In this, research article, the history of cinema, the introduction of cinema in the subcontinent, history of Pakistani cinema, and downfall and reasons for downfall were discussed. In addition, it was deeply explained that there is a revival or survival of Pakistani film industry. Qualitative and quantitative research was conducted. For qualitative research, articles available on the internet were reviewed and an in-depth interview was conducted. On the contrast, for quantitative research, a survey which included 15 close-ended questions was held. The study highlights that people, especially Karachiiets, watch more Hollywood films as compared to Pakistani, and most of the people have no interest in films. In addition, it was concluded that the major reason people of Pakistan don't want to watch Pakistani films because they think that they are copying Indian culture nevertheless, moral value, ethic, norm, language (except religion) are same. It is concluded that people do not want to waste their time and money to go to the cinema; they prefer to watch films at home. As per the theory "uses and gratification", Pakistani cinema is making most of the films as per the interest of people such as they want to use item song or not. Moreover, social issues, romantic and comedy films are the major tools to influence people by inciting ideas. While cultivation theory says, people will soon addict to watch dance items, short dresses, focus on social issues, women empowerment, etc. therefore, as per the scenario, film director, producer and scriptwriter will invest time and money in productive use like for them and for society. 


\section{References}

Aijaz, Rahul. Na Maloom Afraad 2 review. September 1, 2017. https://tribune.com.pk/story/1496720/na-maloom-afraad-2-reviewentertaining-soulless/.

一. THE EXPRESS TRIBUNE . December 20, 2017. https://tribune.com. $\mathrm{pk} /$ story/1588456/4-rangreza-review-musical-gets-narrative-rhythmwrong/.

Ali, Khan:Ali,Nobil,Ahmed. Cinema and Society: Film and Social Change in Pakistan. Oxford University Press, 2016.

Ashraf, Sonia. Review: Mehrunisa V Lub U. June 24, 2017. https://images.d awn.com/news/1177883/review-mehrunisa-v-lub-u-is-an-eid-film-thewhole-family-cant-watch-together.

Aslam. Lollywood - Pakistani Cinema Through A Transitional Lens. 2016. https://web.b.ebscohost.com/abstract?direct=true $\&$ profile=ehost $\&$ scope $=$ sit e\&authtype $=$ crawler \&jrnl $=19984162 \& A N=117676327 \& \mathrm{~h}=\mathrm{j} 3 \mathrm{GhOr} 7 \mathrm{fsTqTh} 5$ 23spH3FKnFfWUQWZrWgoPu8c9cwj6l3xmw\%2bKtCGqAFcJkdWk9\%2fsHhj Ljn\%2bOfvZKIvEc0vEdA\%3d\%3d\&crl=c\&resultNs=AdminWebAuth\&resultL o.

Clarke, R. Research Models and Methodologies . University of Wollongong (UOW), 2005.

Erum, Hafeez. Pakistani Cinema through a transitional lens. June 2015. https://www.researchgate.net/publication/303898261_Pakistani_Cinema_t hrough_a_transitional_lens.

Geoffrey, Nowell-Smith. The History of Cinema: A Very Short Introduction. Oxford University Press, 2017.

Ghafoor, Usman. Pakistan's dilemma - Bollywood or bust? June 9, 2005. http://news.bbc.co.uk/2/hi/south_asia/4617447.stm.

HASAN, MEHREEN. Balu Mahi proves Pakistan can't stomach love without marriage. February 16, 2017.

https://images.dawn.com/news/1177080. 
Hassan, Zaidi. What makes the revival of Pakistani cinema an uphill task. February 10, 2017. https://herald.dawn.com/news/1153991.

Javed, Aiman. Film Review: 'Chain Aye Na'. August 17, 2017.

https://www.youlinmagazine.com/story/film-chain-aye-na-review/OTE0.

Mahmood, Rafay. Chalay Thay Saath review: A beautifully bad film. Aril 21, 2017. https://tribune.com.pk/story/1390043/chalay-thay-sath-reviewbeautifully-bad-film/.

-. Yalghaar review. june 22, 2017.

https://tribune.com.pk/story/1441941/yalghaar-review-bullets-bombsbad-storytelling/.

Malani, Gaurav. Khuda Kay Liye: Movie Review. March 31, 2008. https://econ omictimes.indiatimes.com/industry/media/entertainment/khuda-kay-liyemovie-review/articleshow/2913371.cms.

masscommtheory.com. Cultivation Theory. 2015. https://masscommthe ory.com/theory-overviews/cultivation-theory/.

Momina, Mindeel. Film Review: Thora Jee Le. January 23, 2017. https://www.youlinmagazine.com/story/film-thora-jee-le-review/NzU0.

Noor-Ul-Ain. Film Review: Saawan. September 19, 2017. https://www .youlinmagazine.com/story/pakistani-film-saawan/OTM4.

Renu, Saran. History of Indian Cinema. Diamond Pocket Books Pvt Ltd, 2017. Sagar, Sami. A Brief History Of Pakistani Film Industry - And Its Revival(S). January 4, 2017. http://blogs.dunyanews.tv/19359/.

Shahid, Sana. Film Review: 'Raasta'. April 3, 2017.

https://www.youlinmagazine.com/story/film-raasta-review/ODA5.

Sundararaj, Theodore,Baskaran. History through the lens: perspectives on South Indian cinema. 2009.

Syed, Arabi,Idid. Uses and Gratifications. July 2012. 
https://www.researchgate.net/publication/299566021_Uses_and_Gratificati ons.

Witka, Amber. The Differences Between Live Theatre And Film. December 12, 2016. https://www.theodysseyonline.com/differences-live-theatre-film.

www. indiacelebrating.com. IMPACT OF CINEMA IN LIFE ESSAY. April 12, 2017. https://www.indiacelebrating.com/essay/impact-of-cinema-in-lifeessay/.

www.iep.utm.edu. The Frankfurt School and Critical Theory. 2015. https://www.iep.utm.edu/frankfur/.

www.reviewit.pk. Punjab Nahi Jaungi - Film Review. September 1, 2017. https://reviewit.pk/punjab-nahi-jaungi-film-review/.

—. Verna - Film Review. November 21, 2017. https://reviewit.pk/verna-filmreview/. 